\title{
Um estudo preliminar da demografia do Rio Grande do Norte colonial: fontes, métodos e resultados
}

\author{
Dayane Julia Carvalho Dias* \\ Carmen Margarida Oliveira Alveal ${ }^{\star \star}$
}

\begin{abstract}
Este artigo pretende realizar um diálogo entre a Demografia e a História, aliando os conhecimentos específicos dessas duas disciplinas, no sentido de um melhor entendimento tanto dos números coletados para a população do Rio Grande do Norte quanto do contexto histórico que explicaria esses números. Portanto, o objetivo desse estudo é apresentar características sociodemográficas da população norte-riograndese na virada do século XVIII para o XIX, por meio dos primeiros mapas de população realizados na segunda metade do século XVIII, como parte da tentativa da política pombalina de conhecer melhor o império português. Assim, são discutidos alguns dados demográficos, como composição da população por sexo, cor/etnia e condição jurídica, da capitania do Rio Grande do Norte, com base em informações produzidas em 1782, 1788, 1801 e 1805, utilizando metodologias da demografia que serão explicitadas e com um diálogo direto com a historiografia da região.
\end{abstract}

Palavras-chaves: Rio Grande do Norte. População. Século XVIII.

\footnotetext{
*Universidade Estadual de Campinas (Unicamp), Campinas-SP, Brasil (dayanejuliacd@gmail.com).

** Universidade Federal do Rio Grande do Norte (UFRN), Natal-RN, Brasil (carmenalveal@uol.com.br).
} 


\section{Introdução}

A colonização do Rio Grande, ${ }^{1}$ em seu início, foi caracterizada por uma economia incipiente e pelas disputas violentas por terras entre indígenas, colonos e missionários, período conhecido como a Guerra dos Bárbaros. Do ponto de vista econômico, em função das condições climáticas não tão favoráveis ao cultivo da cana como nas capitanias de Pernambuco, Itamaracá e Paraíba, quase não havia engenhos que manufaturassem o açúcar. O Rio Grande acabou tornando-se uma região na qual a atividade da pecuária era a mais relevante, sendo importante fornecedor de carne e couro para as capitanias vizinhas e mesmo a da Bahia. Além do gado, também estava presente uma importante cultura de abastecimento, na qual a produção de farinha de mandioca era protagonista. Por desenvolver atividades nem tanto atrativas, seu crescimento populacional não foi tão grande quanto o de capitanias consideradas mais centrais, como Pernambuco, Bahia, Rio de Janeiro e Minas Gerais; essa última, embora criada apenas do século XVIII, com a descoberta do ouro, fomentou uma migração enorme para as áreas de mineração. Já o Rio Grande permaneceu crescendo a passos lentos.

Este artigo pretende realizar um diálogo entre a Demografia e a História, aliando os conhecimentos específicos dessas duas disciplinas, no sentido de um melhor entendimento tanto dos números coletados para a população do Rio Grande, quanto do contexto histórico que explicaria esses números. Portanto, o objetivo desse estudo é apresentar características sociodemográficas da população norte-riograndese na virada do século XVIII para o XIX, por meio dos primeiros mapas de população realizados na segunda metade do século XVIII, como parte da tentativa da política pombalina de conhecer melhor o império português (MATOS; SOUZA, 2015).

A utilização desses mapas de população, que até pouco tempo atrás eram pouco empregados, destacando-se os estudos de Dauril Alden (1963) e de Maria Luiza Marcílio (2000), entre outros, tem sido encorajada por meio do projeto Counting Colonial Populations: demography and the use of statistics in the Portuguese Empire, 1776-1890, coordenado pelo Dr. Paulo Matos, do Centro de História d’Aquém e d’Além Mar, vinculado à Universidade Nova de Lisboa. ${ }^{2}$ Assim, todos os mapas do império português produzidos no período focado pelo projeto estão disponíveis on-line e possibilitam novos estudos demográficos, com novas metodologias que têm sido desenvolvidas por esta área.

A origem da utilização da demografia como instrumento da escrita e metodologia da história tinha privilegiado a análise dos registros paroquiais, cujo uso remonta ao século XX. De acordo com Maria Luiza Marcílio (2004), o francês Louis Henry, engenheiro, estatístico e demógrafo da população francesa, foi incumbido pelo Ined (Institut National

\footnotetext{
${ }^{1}$ A capitania era denominada apenas de Rio Grande até 1739 quando foi acrescido o termo norte. Assim, ao longo do texto apenas quando a temporalidade passa, especificamente, dessa data, utilizar-se-á Rio Grande do Norte. Entretanto, de maneira genérica, algumas vezes referir-se-á a Rio Grande.

${ }^{2} 0$ projeto pode ser acessado em: 〈http://colonialpopulations.fcsh.unl.pt/index.html〉.
} 
Etudes Démographiques), depois da Segunda Guerra Mundial, para pesquisar a causa de a fecundidade da população francesa ser a mais baixa do mundo. No decorrer da pesquisa, Louis Henry percebeu que seria preciso recorrer à análise demográfica da população anterior ao século XX, sendo que as fontes disponíveis para a análise seriam os registros paroquiais. Com os resultados, foi possível o surgimento do método de reconstituição de família e, com ele, de uma nova ciência: a demografia histórica. ${ }^{3}$

No Brasil, Sheila de Castro Faria (1997) dissertou sobre a história da família e demografia histórica. A autora aborda a importância dos resultados da demografia histórica para o estudo da história da família, salientando que isso foi possível somente graças à documentação dos registros paroquiais de casamentos, batismos e óbitos realizados pela Igreja, que possibilitam uma análise aprofundada com base na demografia histórica.

No período colonial, a Igreja constituía-se em uma peça fundamental na sociedade, cujos procedimentos de casamentos, batismos e óbitos tornavam-se obrigatórios para quem fizesse parte da esfera política, administrativa e social do império português, para se enquadrar no modelo social imposto. Foi com o desenvolvimento da demografia histórica a partir de 1950 e com a utilização dos registros de casamentos, óbitos e batizados que o estudo das famílias e outras áreas se consolidou, incluindo os estudos da família escrava no Brasil.

Entretanto, conforme mostram os autores portugueses Paulo Matos e Paulo Sousa (2015, p. 75), a partir do período pombalino passou a se tentar uma "recolha e produção de informação quantitativa organizada sobre a população", com vistas a conhecer melhor as estatísticas da população e da produção e daí possibilitar a formulação de modelos de ocupação do território, visando sempre o melhor desenvolvimento do império.

Mesmo com os esforços realizados pelas autoridades coloniais na elaboração desses mapas, sabe-se que há falhas no seu levantamento. Assim, os mapas de 1782, 1788, 1801 e 1805 foram utilizados como base, porém, tiveram que ser corrigidos, utilizando-se para tanto o Censo de 1872, considerado mais acurado. 0 artigo inicia-se apresentando os dados e a metodologia utilizada para os resultados alcançados, para depois passar à análise e posteriormente utilizar a História para conjecturar e corroborar os resultados obtidos, no sentido de explicar o contexto histórico.

\section{Fontes, metodologias e dados}

Os dados foram obtidos dos mapas constantes no projeto Counting Colonial Populations. Para a capitania do Rio Grande do Norte foram utilizados quatro mapas, além do recenseamento de 1872:

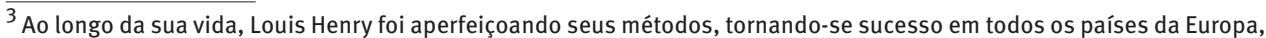
América Latina e Ásia. Os resultados foram expostos em seus manuais, o primeiro deles: Nouveau manuel de depouillement et d' etat civil ancien (HENRY; FLEUREY, 1965).
} 
- 1782 - Mapa, que mostra o número dos habitantes [das qua]tro Capitanias deste Governo, a saber, Pernambuco, Paraíba, Rio Grande, e Ceará, o seguinte Freguesias de que se compõem as cinco Comarcas Eclesiásticas (AHU-PA-Pernambuco, Cx. 145, Doc. 10638);

- 1788 - Mapa que mostra o № de Habitantes das quatro Capitanias deste Governo: Pernambuco, Paraíba, Rio Grande e Ceará divididas nas 5 Comarcas Eclesiásticas (AHU-PA-Pernambuco, Cx. 178, Doc. 12472);

- 1801 - Mappa Geral da Importação de Produtos, e Manufacturas do Reino Produção, Consunmo, Exportação, Portos de donde vierão e para onde forão Habitantes e oocupações delles, Casamentos, Nascimentos, Mortos e dos Indios domesticos, e suas idades. Tabellas das doenças com q(ue) falecerão, previstas e não previstas. Rezumo das quantias emformado na Capitania do Rio grande do Norte no Anno de 1801 (AHU - PA - Rio Grande do Norte, Cx. 9, Doc. 565);

- 1805 - Mapa geral da Importação, produções e Manufaturas do Reino, Produção, consumo [...?]ação e do ficou em ser sem se exportar nem consumir. Portos de donde [...?...] Dos Habitantes e suas occupaçoues, Cazamentos, Nascimentos, e Mortos. Dos Indios de Mesticos com as mesmas declarações. Tabela das moléstias [...] pertencente ao anno de 1805, feito em o Mes de Outubro de 1806 (AHU - PA - Rio Grande do Norte, Cx. 10, Doc. 629);

- Recenseamento geral do império de 1872. População presente para a província do Rio Grande do Norte por idade, sexo e condição jurídica. Dados ajustados pelo Centro de Desenvolvimento e Planejamento Regional (Cedeplar), da Universidade Federal de Minas Gerais (UFMG), disponíveis on-line.

Embora existam outras fontes que possibilitem a verificação de alguns dados de população, esses mapas foram escolhidos pela forma como dispuseram as informações, permitindo a sistematização que será apresentada a seguir.

Com relação à metodologia aplicada, foram realizadas estimativas de população de 1801 e 1805 não somente por idade e sexo, mas também por categoria de composição jurídica e cor/etnia. ${ }^{4}$ Para a correção, alguns pressupostos foram adotados e etapas seguidas. Em relação ao contexto histórico e demográfico do período, é conhecido que até 1970 a população brasileira era considerada quase estável. Isso significa que até essa data não houve mudança significativa na estrutura etária brasileira, pois as taxas vitais mantinham-se praticamente constantes. Apesar do declínio acentuado da mortalidade a partir de 1940, a fecundidade manteve-se em níveis elevados (CARVALHO, 1980, 2004; CARVALHO; SAWYER; RODRIGUES, 1998).

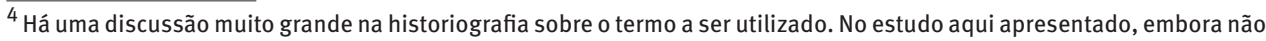
seja foco da discussão, preferiu-se utilizar o termo cor/etnia, uma vez que havia uma certa confusão. Sobre esse assunto ver Schwarcz (1993), Machado (2008), Paiva (2008, 2015) e Viana (2007).
} 
Nesta perspectiva, tem-se como hipótese que a população do Rio Grande também se assemelhava ao padrão brasileiro. Assim, para as estimativas de 1801 e 1805, supondo-se que o crescimento populacional era constante no período analisado, a população de 1872 foi decrementada a uma taxa de crescimento anual de $2,4 \%$ para a população livre e de $-0,01 \%$ para a escrava (RODARTE, 2008).

Mário Rodarte (2008) estimou taxas de crescimento para o Brasil e províncias para o período de 1832 a 1872. Os dados para o Brasil apresentaram, para o período, uma taxa de $2,2 \%$ para a população livre e de $0,0 \%$ para os escravos. As taxas de crescimento para o Rio Grande do Norte, durante o mesmo período, foram de, respectivamente, 2,4\% e - $0,1 \%$. Para estimar as taxas do Rio Grande do Norte, Rodarte (2008) utilizou estimativas de contagens populacionais realizadas pelo conselheiro Antônio Rodrigues Velloso de Oliveira, adaptadas para os limites provinciais da década de 1870 por Joaquim Noberto de Souza (1986 apud RODARTE, 2008). Nesse cálculo excluiu-se a suposição da existência de 800.000 índios. Além disso, pautou-se pela contagem regional do Rio Grande do Norte de 1855, levantada por Botelho (1998 apud RODARTE, 2008). Portanto, são dados que requerem cautela com sua utilização, pois foram realizados com base em contagens populacionais que possuem baixa qualidade, tornando-se uma limitação ao estudo.

Para organizar as idades em grupos quinquenais do censo de 1872, foram aplicados os multiplicadores de Karup-King, que consistem em uma técnica de interpolação que permite, por meio de multiplicadores, desagregar informações de grupos quinquenais ou decenais em idades simples de determinada população ao longo do ano calendário. ${ }^{5}$

As contagens de índios estão presentes nos mapas populacionais de 1801 e 1805, no entanto, no censo de 1872 essa categoria é ausente (pelo menos de forma explícita), então essa população não foi estimada. Por sua vez, a categoria de "cablocos" presente no censo de 1872 não consta nos mapas de 1801 e 1805. Mas ambas as categorias foram incluídas em análises de população total observada e estimada.

É importante ressaltar que se trata de um período de ocorrência de intensos fluxos migratórios do Norte do Brasil em direção a outras partes, o que poderia comprometer a aplicação do método de estimar população, já que o conceito de estabilidade está diretamente relacionado à ausência de migração. Dessa forma, nos resultados a princípio serão apresentados os dados estimados e observados (sem correção), que permitiram a análise de: estimativas de população por idade, sexo, composição de cor /etnia e condição jurídica para 1801 e 1805; razão de sexo; estrutura etária (pirâmides); e evolução da população de 1782 a 1805.

Conforme já dito anteriormente, os dados estimados são obtidos com base em métodos que apresentam pressupostos e limitações, o que não representa a realidade total da época. São estimativas que variam de acordo com a taxa de crescimento utilizada e a qualidade das informações. Como as taxas de crescimento empregadas aqui são baseadas em contagens

\footnotetext{
$\overline{5}$ Para mais informações do método consultar Judson e Popoff (2004).
} 
populacionais que possuem baixa qualidade, devido ao alto índice de sub-registros, ${ }^{6}$ os resultados são aproximações. Apesar das dificuldades, o esforço de correção é válido, uma vez que possibilita a problematização desses dados.

Diante disso, as informações são apresentadas a partir de dados observados (dados brutos) e estimados, no sentido de fornecer comparações. Como se trata de duas populações completamente diferentes (livre e escrava), foram utilizadas duas taxas de crescimento. Tanto em 1801 como em 1805, os dados estimados foram superiores aos observados para as duas populações. Esse resultado geral indica que, se de fato o pressuposto de estabilidade e essas taxas de crescimento são válidos, as estimativas deste estudo podem ser consideradas mais acuradas do que os registros dos mapas de população, ou seja, elas se aproximam mais do verdadeiro tamanho populacional do Rio Grande do Norte nos anos analisados. Se adotarmos essa população estimada como representativa da época, é possível considerar que os dados de população observados de 1801 e 1805 encontram-se sub-registrados, por isso a importância da aplicação de estimativas populacionais. Uma boa medida que indica a porcentagem da população contabilizada pelos mapas em relação àquela que foi estimada neste estudo é o grau de cobertura.

A Tabela 1 apresenta os dados de população total observados e estimados, a diferença absoluta entre eles e o grau de cobertura, que corresponde à razão entre a população observada e a estimada. Percebe-se que a diferença mais ampla entre a população observada e a estimada ocorre em 1801. Quanto mais antigo no tempo, maior é a incidência de problemas nos dados, por isso, em 1801 o grau de cobertura foi de apenas $55 \%$ e indica que talvez um pouco mais da metade da população do Rio Grande do Norte tenha sido contabilizada no mapa de 1801. Em 1805 a diferença entre os dados observados e os estimados foi bem menor, o que resultou em um grau de cobertura de $85 \%$. Essa diferença pode ser explicada, em grande medida, em relação à taxa de crescimento utilizada; apesar de não ter chegado a $100 \%$ de cobertura, as taxas utilizadas foram condizentes.

TABELA 1

População total observada e estimada e grau de cobertura Rio Grande do Norte - 1801-1805

\begin{tabular}{lcc}
\hline \multicolumn{1}{r}{ População } & 1801 & 1805 \\
\hline Observada & 29.443 & 49.250 \\
Estimada & 54.016 & 57.969 \\
Diferença & 24.573 & 8.719 \\
Grau de cobertura (\%) & 55,0 & 85,0 \\
\hline
\end{tabular}

Fonte: 1801: AHU-PA-Rio Grande do Norte, Caixa 9, Documento 565; 1805 : AHU-PA-Rio Grande do Norte, Caixa 10 , Documento 629.

Os resultados fornecidos pelas Tabelas 2 e 3 permitem identificar de forma mais detalhada a diferença entre os dados estimados e observados da população do Rio Grande do Norte por sexo, idade, cor/etnia e condição jurídica, em 1801 e 1805.

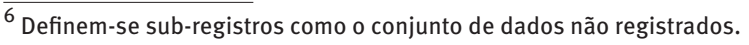


Em 1801, entre a população de livres, a existência de pessoas nas categorias de cor pardo e preto é muito maior do que de pessoas brancas, tanto nos dados observados como nos estimados. Em relação aos escravos, a categoria de preto é superior à de pardo, embora esta última tenha aumentado substancialmente no período analisado (de 560 para 3.371 homens e de 607 para 3.470 mulheres). Essa diferença permite analisar que poderia ter sido utilizada uma taxa de crescimento diferente também para a população por cor (Tabela 2). Em 1805, essa tendência se repetiu, embora as diferenças entre os dados observados e estimados tenham sido menores, exceto também pela população de escravos pardos e pretos.

De modo geral, esses mapas permitem analisar que, em 1801 e 1805, o número de pessoas pardas e pretas na população era superior ao de pessoas brancas. Certamente, esta é uma tendência que se repetiria por outras partes da colônia e justifica o que mais tarde seria a política de branqueamento da população mediante a promoção da imigração europeia, que era parte de um contexto de reconstrução das relações de trabalho no Brasil e busca de um ideal de civilização nas últimas décadas do século XIX (CHALHOUB, 1996).

TABELA 2

População observada e estimada, por condição jurídica e cor/etnia, segundo sexo e grupos de idade Rio Grande do Norte - 1801

\begin{tabular}{|c|c|c|c|c|c|c|c|c|c|c|}
\hline \multirow{3}{*}{$\begin{array}{l}\text { Sexo e grupos } \\
\text { de idade }\end{array}$} & \multicolumn{6}{|c|}{ Livres } & \multicolumn{4}{|c|}{ Escravos } \\
\hline & \multicolumn{3}{|c|}{ População observada } & \multicolumn{3}{|c|}{ População estimada } & \multicolumn{2}{|c|}{$\begin{array}{l}\text { População } \\
\text { observada }\end{array}$} & \multicolumn{2}{|c|}{$\begin{array}{c}\text { População } \\
\text { estimada }\end{array}$} \\
\hline & Brancos & Pardos & Pretos & Brancos & Pardos & Pretos & Pardos & Pretos & Pardos & Pretos \\
\hline \multicolumn{11}{|l|}{ Homens } \\
\hline 0 a 4 anos & 687 & 858 & 130 & 1.224 & 1.095 & 309 & 106 & 231 & 455 & 557 \\
\hline 5 a 9 anos & 624 & 350 & 176 & 922 & 753 & 152 & 100 & 213 & 320 & 305 \\
\hline 10 a 19 anos & 894 & 1.079 & 274 & 2.009 & 1.624 & 393 & 122 & 530 & 788 & 632 \\
\hline 20 a 29 anos & 669 & 651 & 174 & 2.084 & 1.776 & 448 & 119 & 458 & 719 & 772 \\
\hline 30 a 39 anos & 459 & 617 & 164 & 1.177 & 867 & 294 & 48 & 323 & 365 & 443 \\
\hline 40 a 49 anos & 929 & 409 & 79 & 960 & 688 & 270 & 48 & 189 & 288 & 392 \\
\hline 50 a 59 anos & 234 & 217 & 83 & 666 & 466 & 166 & 9 & 94 & 214 & 228 \\
\hline 60 a 69 anos & 117 & 121 & 42 & 385 & 288 & 93 & 3 & 48 & 119 & 110 \\
\hline 70 a 79 anos & 53 & 59 & 29 & 115 & 110 & 48 & 4 & 14 & 61 & 56 \\
\hline 80 a 89 anos & 19 & 19 & 5 & 40 & 56 & 19 & 1 & 11 & 30 & 31 \\
\hline 90 anos e mais & 0 & 2 & 1 & 22 & 33 & 14 & 0 & 2 & 12 & 15 \\
\hline Total & 4.685 & 4.382 & 1.157 & 9.604 & 7.756 & 2.207 & 560 & 2.113 & 3.371 & 3.541 \\
\hline \multicolumn{11}{|l|}{ Mulheres } \\
\hline 0 a 4 anos & 642 & 812 & 145 & 1.203 & 1.151 & 322 & 113 & 190 & 488 & 500 \\
\hline 5 a 9 anos & 626 & 816 & 132 & 917 & 765 & 150 & 110 & 201 & 356 & 311 \\
\hline 10 a 19 anos & 813 & 1.146 & 306 & 1.996 & 1.694 & 396 & 112 & 406 & 718 & 698 \\
\hline 20 a 29 anos & 744 & 1.319 & 247 & 1.997 & 1.691 & 440 & 145 & 457 & 713 & 770 \\
\hline 30 a 39 anos & 573 & 644 & 134 & 1.051 & 868 & 230 & 53 & 282 & 402 & 415 \\
\hline 40 a 49 anos & 333 & 372 & 108 & 890 & 704 & 216 & 38 & 133 & 319 & 310 \\
\hline 50 a 59 anos & 234 & 193 & 90 & 563 & 431 & 133 & 27 & 61 & 189 & 210 \\
\hline 60 a 69 anos & 88 & 115 & 58 & 318 & 255 & 86 & 7 & 33 & 108 & 172 \\
\hline 70 a 79 anos & 51 & 71 & 23 & 73 & 99 & 43 & 1 & 12 & 46 & 55 \\
\hline 80 a 89 anos & 18 & 27 & 12 & 34 & 33 & 14 & 1 & 6 & 12 & 21 \\
\hline 90 anos e mais & 2 & 3 & 1 & 15 & 19 & 7 & 0 & 0 & 5 & 6 \\
\hline Total & 4.124 & 5.518 & 1.256 & 9.056 & 7.708 & 2.036 & 607 & 1.781 & 3.357 & 3.470 \\
\hline
\end{tabular}

Fonte: AHU-PA-Rio Grande do Norte, Caixa 9, Documento 565. 
TABELA 3

População observada e estimada, por condição jurídica e cor/etnia, segundo sexo e grupos de idade Rio Grande - 1805

\begin{tabular}{|c|c|c|c|c|c|c|c|c|c|c|}
\hline \multirow{3}{*}{$\begin{array}{l}\text { Sexo e grupos de } \\
\text { idade }\end{array}$} & \multicolumn{6}{|c|}{ Livres } & \multicolumn{4}{|c|}{ Escravos } \\
\hline & \multicolumn{3}{|c|}{ População observada } & \multicolumn{3}{|c|}{ População estimada } & \multicolumn{2}{|c|}{$\begin{array}{l}\text { População } \\
\text { observada }\end{array}$} & \multicolumn{2}{|c|}{$\begin{array}{c}\text { População } \\
\text { estimada }\end{array}$} \\
\hline & Brancos & Pardos & Pretos & Brancos & Pardos & Pretos & Pardos & Pretos & Pardos & Pretos \\
\hline \multicolumn{11}{|l|}{ Homens } \\
\hline 0 a 4 anos & 2.022 & 2.610 & 160 & 1.345 & 1.204 & 339 & 165 & 817 & 453 & 555 \\
\hline 5 a 9 anos & 1.202 & 1.041 & 182 & 1.014 & 828 & 168 & 69 & 474 & 319 & 304 \\
\hline 10 a 19 anos & 1.427 & 1.603 & 278 & 2.209 & 1.786 & 433 & 154 & 487 & 785 & 630 \\
\hline 20 a 29 anos & 1.334 & 1.255 & 183 & 2.291 & 1.953 & 493 & 137 & 504 & 716 & 769 \\
\hline 30 a 39 anos & 973 & 1.096 & 152 & 1.294 & 953 & 323 & 157 & 273 & 364 & 442 \\
\hline 40 a 49 anos & 851 & 523 & 156 & 1.056 & 756 & 297 & 55 & 182 & 287 & 390 \\
\hline 50 a 59 anos & 433 & 347 & 78 & 732 & 513 & 183 & 22 & 99 & 213 & 227 \\
\hline 60 a 69 anos & 209 & 211 & 53 & 424 & 316 & 102 & 16 & 50 & 119 & 109 \\
\hline 70 a 79 anos & 99 & 74 & 20 & 127 & 121 & 53 & 3 & 21 & 61 & 56 \\
\hline 80 a 89 anos & 34 & 7 & 11 & 44 & 61 & 21 & 2 & 4 & 30 & 31 \\
\hline 90 anos e mais & 9 & 3 & 2 & 24 & 36 & 15 & 0 & 0 & 12 & 15 \\
\hline Total & 8.593 & 8.770 & 1.275 & 10.560 & 8.527 & 2.426 & 780 & 2.911 & 3.358 & 3.527 \\
\hline \multicolumn{11}{|l|}{ Mulheres } \\
\hline 0 a 4 anos & 1.876 & 2.802 & 99 & 1.322 & 1.265 & 354 & 95 & 658 & 487 & 498 \\
\hline 5 a 9 anos & 1.179 & 1.184 & 85 & 1.008 & 841 & 165 & 96 & 525 & 355 & 310 \\
\hline 10 a 19 anos & 1.525 & 1.358 & 196 & 2.194 & 1.862 & 435 & 165 & 499 & 715 & 695 \\
\hline 20 a 29 anos & 1.249 & 1.094 & 203 & 2.196 & 1.859 & 484 & 146 & 541 & 710 & 767 \\
\hline 30 a 39 anos & 1.037 & 1.219 & 199 & 1.155 & 954 & 253 & 90 & 271 & 400 & 414 \\
\hline 40 a 49 anos & 680 & 490 & 186 & 978 & 774 & 237 & 45 & 186 & 318 & 309 \\
\hline 50 a 59 anos & 435 & 399 & 83 & 619 & 473 & 146 & 32 & 114 & 188 & 210 \\
\hline 60 a 69 anos & 195 & 209 & 57 & 349 & 280 & 94 & 17 & 44 & 108 & 171 \\
\hline 70 a 79 anos & 88 & 104 & 28 & 81 & 108 & 48 & 5 & 11 & 46 & 55 \\
\hline 80 a 89 anos & 34 & 11 & 10 & 37 & 37 & 15 & 2 & 7 & 12 & 21 \\
\hline 90 anos e mais & 9 & 4 & 3 & 16 & 20 & 8 & 1 & 1 & 5 & 6 \\
\hline Total & 8.307 & 8.874 & 1.149 & 9.957 & 8.475 & 2.239 & 694 & 2.857 & 3.344 & 3.456 \\
\hline
\end{tabular}

Fonte: AHU-PA-Rio Grande do Norte, Caixa 10, Documento 629.

Passando para uma análise da razão de sexo, ${ }^{7}$ a despeito de alguns momentos de pouco equilíbrio, pode-se afirmar que a população do Rio Grande esteve medianamente equilibrada entre a população livre, com uma razão de sexo abaixo de 100 entre as idades de 0 a 19 anos, o que indica a presença de mais mulheres na população estimada do que de homens. A partir dos 20 anos até a idade idosa, há predominância de homens na população, com uma razão de sexo superior a 100, chegando no grupo etário com uma razão de 163,7 (Gráfico 1).

\footnotetext{
${ }_{7}^{7}$ razão de sexo expressa a relação quantitativa entre homens e mulheres: se é igual a 100, os números entre os sexos se igualam; acima de 100, há predominância do sexo masculino na população; e abaixo de 100 existe predominância do sexo feminino. Quanto maior a discrepância entre os sexos, maior o desequilíbrio, podendo acarretar consequências demográficas. Esse indicador é influenciando por taxas de migração e de mortalidade diferenciadas por sexo e idade. Geralmente, as mulheres são maioria em muitas populações, reflexo da sobremortalidade masculina, principalmente nas idades jovens e adultas, decorrente do alto índice de causas violentas de óbitos (SHRYOCK; SIEGEL, 1976; CERQUEIRA; GIVISIEZ, 2004).
} 
Entre a população escrava estimada, a razão de sexo apresentou oscilações de um grupo etário para outro, principalmente a partir da faixa de 50 a 59 anos, chegando a uma maior oscilação no grupo etário de 90 anos e mais, com uma razão de sexo de 227,3, ou seja, 27 homens para cada 10 mulheres.

Tanto para a população livre quanto para a escrava, a razão de sexo entre a idade adulta e principalmente idosa representou predominância de homens, especialmente entre os escravos. Estes resultados revelam que os dados apresentam falhas em seu levantamento. Para uma economia de abastecimento e de pecuária, como é o caso do Rio Grande do Norte, é curioso esse fato, uma vez que, em geral, era em áreas de grande lavoura que havia predomínio masculino. Além disso, as mulheres costumam ser maioria nas populações, principalmente no final da vida adulta e idosa, em decorrência da alta mortalidade masculina, geralmente por causas externas, como a violência. Mas, como se trata de um período marcado pela alta mortalidade ocasionada pela disseminação de doenças infecciosas, talvez a mortalidade entre os sexos não apresentasse tanta diferença. De todo modo, é importante destacar que a razão de sexo também pode ser um indicador de problemas nos dados e, neste caso, fica clara a existência de falha no levantamento dos dados, tanto para os homens como para as mulheres, não cabendo uma análise mais apurada a partir desse resultado.

GRÁFICO 1

Razão de sexo, por condição jurídica (dados estimados)

Rio Grande do Norte - 1801-1805

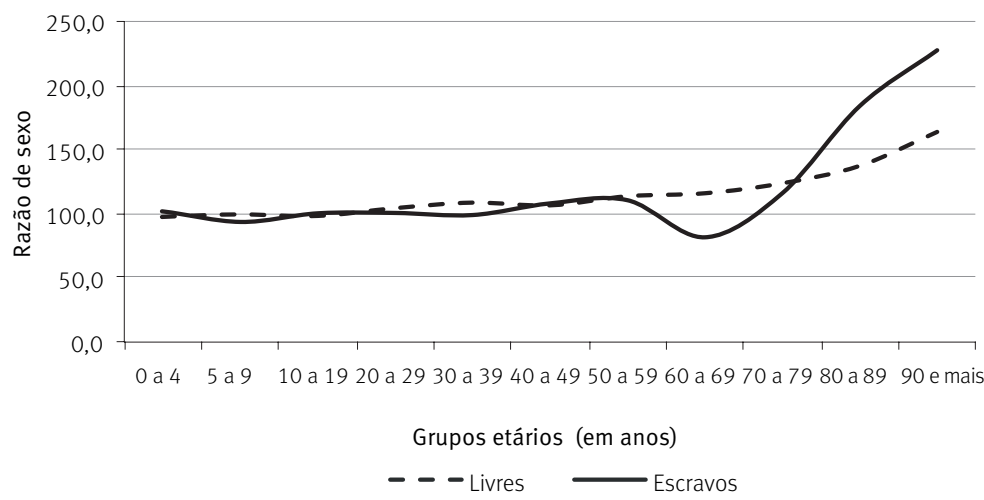

Fonte: 1801: AHU-PA-Rio Grande do Norte, Caixa 9, Documento 565; 1805: AHU-PA-Rio Grande do Norte, Caixa 10, Documento 629.

Ainda com relação à faixa etária da população do Rio Grande do Norte, com base nos dados estimados para 1801 e 1805, foi elaborado o Gráfico 2, no sentido de permitir uma melhor visualização do equilíbrio da razão de sexo, analisado anteriormente.

A pirâmide etária é um instrumento valioso para a análise da composição da população por idade e sexo. A estrutura etária de uma pirâmide é determinada pela influência de três fatores: nascimentos, mortalidade e migrações. Cabe ressaltar o pequeno número de pessoas no grupo etário de 5 a 9 anos, tanto em 1801 como em 
1805. Isso mostra que, mesmo com dados estimados, os grupos etários de 0 a 4 anos e de 5 a 9 anos foram os mais atingidos pela incidência de sub-registros. Esses grupos mais jovens (assim como os de idosos), geralmente, são os mais vulneráveis a erros de declaração (Gráfico 2).

GRÁFICO 2

População, por sexo e grupos etários (dados estimados) Rio Grande do Norte - 1801-1805

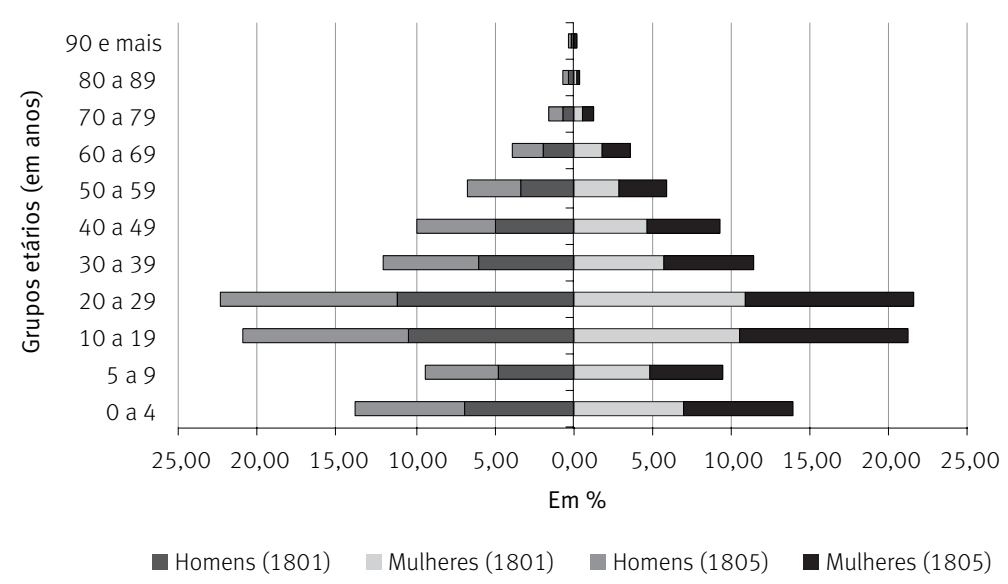

Fonte: 1801: AHU-PA-Rio Grande do Norte, Caixa 9, Documento 565; 1805 : AHU-PA-Rio Grande do Norte, Caixa 10, Documento 629.

Para verificar a evolução da população entre 1782 e 1805, foram utilizados os dados observados, no que se chegou ao Gráfico 3. Deve-se explicar que, para efeito de comparação com 1782 e 1788 (que não tiveram os dados corrigidos), foi preferível analisar os dados brutos.

GRÁFICO 3

Evolução da população (dados observados)

Rio Grande do Norte - 1782-1805

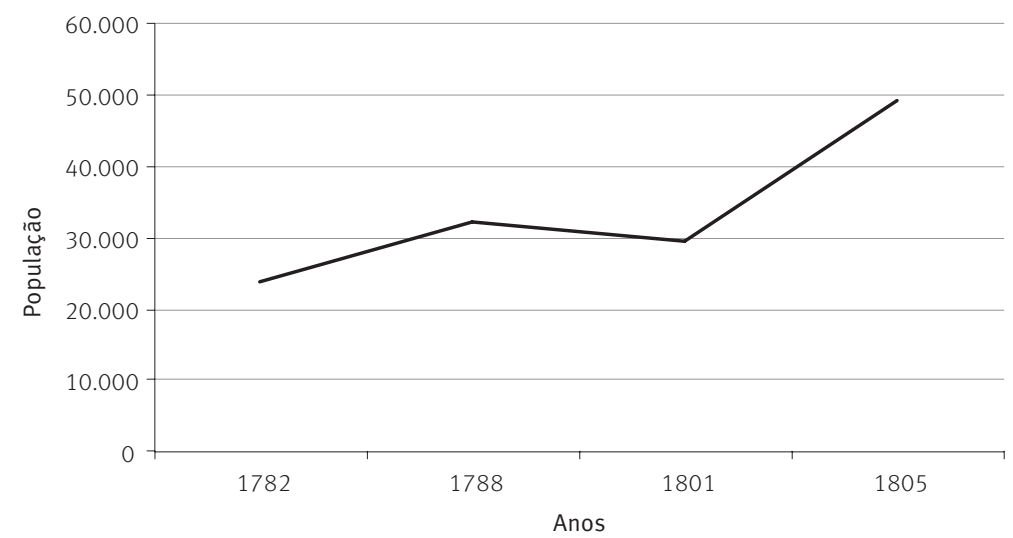

Fonte: AHU-PA-Pernambuco, Caixa 145, Documento 10638; AHU-PA-Pernambuco, Caixa 178, Documento 12472; AHU-PA-Rio Grande do Norte, Caixa 9, Documento 565; AHU-PA- Rio Grande do Norte, Caixa 10, Documento 629. 
Dos dados mostrados até o momento, esse é o que mais contribui para se analisar do ponto vista histórico o contexto desses números. Entre 1782 e 1788, a população total da capitania do Rio Grande do Norte passou de 23.812 para 32.038 pessoas, com um aumento de 34,5\%. No início do século XIX, a população norte-riograndense correspondia a 29.443 em 1801, aumentando para 49.250 em 1805, o que representa um crescimento de $67,3 \%$. Porém na virada do século, entre 1788 e 1801, houve uma diminuição da população na ordem de $9 \%$. Mais a diante tentar-se-á entender à luz da História se tais números podem ser corroborados.

\section{0 contexto histórico}

O início do povoamento do território do atual estado do Rio Grande do Norte ocorreu a partir da necessidade de se proteger a colônia que, desde o último quartel do século XVI, começava a gerar grandes lucros com a produção de açúcar. Era preciso prover segurança e proteção aos engenhos de cana-de-açúcar presentes na capitania de Pernambuco e Itamaracá. No final deste século, foram iniciadas expedições de conquista que culminaram na criação da capitania da Paraíba e na povoação da capitania do Rio Grande (BATISTA, 2012; GONCALVES, 2007), apesar de a costa já ser constantemente visitada, sobretudo, pelos franceses.

Já em princípios do século XVII, houve uma tentativa de um povoamento efetivo, tendo como uma forma de fomentar a vinda de conquistadores a distribuição de sesmarias, títulos de terra que foram concedidos praticamente todos na região litorânea da capitania, o chamado litoral oriental potiguar. ${ }^{8}$ As terras em sesmarias eram dadas principalmente para a criação de gado e roçado, mas também eram distribuídas áreas de pescaria. A cidade do Natal já havia sido fundada a partir da construção da fortaleza dos Reis Magos, em 1599 (CASCUDO, 2011). Nesta época, a única freguesia existente era a de Nossa Senhora de Apresentação, com sede na recém-fundada cidade do Natal.

Das 185 sesmarias distribuídas, muitas indicavam a obrigatoriedade de se construir uma casa na cidade no período de seis meses, indicando o interesse em que a cidade se desenvolvesse e se tornasse um polo de atração para a região conquistada recentemente. Contudo, a averiguação realizada em 1614 mostra que pouquíssimas casas tinham sido erguidas, ficando a cidade do Natal com poucas habitações. ${ }^{9}$ Por meio dessas cartas, sabe-se da chegada dos primeiros escravos africanos na capitania. Os jesuítas trouxeram quatro escravos da guiné, e ainda a indicação de que um sesmeiro também “possuía escravos”. Porém, a produção de açúcar no Rio Grande não tomou as mesmas proporções que teve

\footnotetext{
8 “Potiguar" é o nome de uma grande nação Tupi que habitava a região litorânea do que atualmente corresponde aos estados do Rio Grande do Norte e da Paraíba. Posteriormente, o termo passou a ser usado como gentílico dos nascidos no estado do Rio Grande do Norte.

9 "Tresllado do auto que mandarão Alexandre de Moura, capitão mor do Pernambuco e ho desembargador Manoel Pinto da Rocha ouvidor geral desta estado para se fazerem as deligencias nelle declaradas” (IHGRN, 2000).
} 
em outras capitanias, como Pernambuco e Paraíba, tendo seu primeiro engenho apenas no início do século XVII, o Cunhaú (GOMES, 1997). ${ }^{10}$

Depois do engenho Cunhaú, foi fundado outro no Rio Grande do Norte, ainda na primeira metade do século XVII, nos vales úmidos do litoral da capitania do Rio Grande, o engenho Potengi, totalizando duas unidades em 1637, na época em que o território estava sob o domínio holandês.

Pode-se afirmar que a produção do açúcar da capitania estagnou-se, não havendo um aumento considerável no número de engenhos até a segunda metade do século XIX. A má qualidade do solo era constantemente evocada como entrave à produção. Os primeiros cronistas chamam a atenção para este fato. Domingos de Veiga, que teria escrito um depoimento em 1627 , ou em 1628, afirmou que havia somente dois engenhos no Rio Grande e que poucas terras eram propícias para o cultivo de cana. Veiga afirmou que havia muitos currais de gado e dois engenhos de açúcar, mas que existia bastante cultura de abastecimento (LYRA, 2008).

Em 1609, o sargento mor Diogo Campos Moreno, em seu Relatório das Praças Fortes, alegava que a terra da capitania era "areiosa", "escalvada" e de pouco proveito para o plantio de cana-de-açúcar, "em cinco e seis léguas ao redor da fortaleza". Por esse motivo, a capitania não era tão povoada como Paraíba "e as demais que tem açúcar e pau-brasil”. Apesar disso, o engenho Cunhaú destacava-se na região (MELLO, 1984).

Os documentos produzidos pela Companhia das Índias Ocidentais (WIC), uma instituição holandesa, descrevem uma realidade não muito diferente. 0 "Relatório sobre o estado das capitanias conquistadas no Brasil”, apresentado por Adriaen van der Dussen ao conselho dos XIX na Câmara de Amsterdam, em 4 de abril de 1640, o "Breve discurso sobre o estado das quatro capitanias conquistadas, de Pernambuco, Itamaracá, Paraíba e Rio Grande, situadas na parte setentrional do Brasil” (1638) e a “Memória oferecida ao Senhor Presidente e mais Senhores do Conselho desta cidade de Pernambuco, sobre a situação, lugares, aldeias e comércio da mesma cidade, bem como Itamaracá, Paraíba e Rio Grande segundo o que eu, Adriaen Verdonck, posso me recordar" (1630) são exemplos destas fontes.

Verdonck, em sua Memória, que possui características de espionagem, afirmou que existia "ainda" um engenho localizado em Cunhaú, cuja produção variava de seis mil a sete mil arrobas de açúcar. Morariam nesta localidade, de acordo com o holandês, de 60 a 70 homens com suas famílias. Por Cunhaú, passavam produtos de subsistência que eram transportados para Pernambuco, tais como gado, farinha e milho. Segundo o funcionário da WIC, o açúcar produzido pelo engenho Cunhaú também era levado para Pernambuco para ser exportado. ${ }^{11}$

\footnotetext{
$\overline{10}$ Há discussão sobre a data de fundação de engenho. A maioria dos autores apresenta a data de 1604. Cascudo (2008) foi mais cuidadoso e afirma que a sesmaria onde seria instalado o engenho foi doada em 2 de maio de 1604, mas não menciona quando teria ocorrido de fato a instalação. Já Ana Maria de Azevedo Souza (2005) coloca a data de 1614, mesmo ano da averiguação das demarcações. Esta mesma autora indica que o engenho Cunhaú foi vendido ao coronel Manuel Ottoni de Araújo Lima e teria voltado a produzir açúcar mascavo de 1920 a 1970.

${ }^{11}$ Memória oferecida ao Senhor Presidente e mais Senhores do Conselho desta cidade de Pernambuco, sobre a situação, lugares, aldeias e comércio da mesma cidade, bem como Itamaracá, Paraíba e Rio Grande segundo o que eu, Adriaen Verdonck, posso me recordar. Escrita em 20 de maio de 1630 (MELLO, 2004).
} 
De acordo com Verdonck, na cidade do Natal havia "gado em abundância", criavam-se porcos e "muitas" galinhas. A cidade contava com bons pastos e seus moradores não teriam outra riqueza senão o gado. Entretanto, a despeito dessas afirmações, o espião da WIC alegava que o povo era miserável, "mal tendo de que viver”. Os habitantes plantavam milho e mandioca para fazer farinha, que eram exportados sempre para Pernambuco. Havia, na cidade, abundância de peixes, animais de caça e frutas silvestres. Verdonck afirma que na jurisdição do Rio Grande, provavelmente referindo-se à região circunvizinha a Natal, havia dois engenhos que fabricavam pouco açúcar. Segundo o holandês, os habitantes mais abastados do Rio Grande viviam em seus sítios, afastados do núcleo urbano. A população da capitania não excedia os 120 ou 130 homens. Na cidade do Natal haveria de 35 a 40 casas de palha e barro (MELLO, 2004).

Adriaen van der Dussen afirmou que, na capitania do Rio Grande, havia quatro freguesias e que a principal atividade econômica era a pecuária, servindo para o abastecimento das outras capitanias. Não se pode crer que houve uma evolução significativa da população do Rio Grande que justificasse a criação de mais três freguesias. A divisão da capitania em quatro freguesias é, antes, um entendimento do relator da WIC sobre a situação da localidade do que resultado de alguma mudança. Dussen continua o seu relatório, alegando que "há muito tempo" existiam dois engenhos na capitania: o Engenho Potengí, que se encontrava arruinado; e o Engenho Cunhaú, que havia sido confiscado e vendido a Willem Beck e Hugo Graswinckel (DUSSEN, 1640, p.137-232). Sendo assim, os primeiros relatos sobre a vida econômica e administrativa da capitania necessitam ser ainda muito estudados, já que a historiografia ainda debate a consistência dos dados por eles informados.

Aparentemente, a economia açucareira no Rio Grande do Norte ter-se-ia estagnado, ficando restrita ao engenho Cunhaú. De fato, a ameaça indígena era uma constante e, na época dos holandeses, é conhecido o massacre de 1645 no engenho Cunhaú e em Utinga (SOUZA, 2005). Após a expulsão dos holandeses em 1654, na segunda metade do século XVII, o interior passou a ser priorizado, culminando na chamada Guerra dos Bárbaros (MEDEIROS, 2009), ${ }^{12}$ quando uma série de expedições foi realizada na tentativa de assegurar o espaço colonial (PUNTONI, 2002). A vinda de conquistadores das áreas de Pernambuco e Paraíba teria contribuído para um crescimento da população, mas que proporcionalmente deve ter equilibrado os números diante dos vários ataques às populações indígenas do interior, chamadas genericamente de tapuias, cujos homens foram alvos de assassinatos, sobrevivendo algumas mulheres e crianças, incorporadas à sociedade colonial, por meio da escravidão. Conforme se avançava para o interior, a região litorânea ao leste passou a ter importância, uma vez que se tornou o grande fornecedor de gêneros alimentícios para as tropas que lutavam no sertão, sobretudo a farinha de mandioca.

\footnotetext{
${ }^{12}$ Segundo Ricardo Pinto de Medeiros (2009), "A partir da segunda metade do século XVII, com o fim da guerra com os holandeses, e afastada a ameaça de invasão externa, intensifica-se o processo de ocupação do sertão, principalmente através da expansão da atividade pecuária. Esta expansão vai provocar uma série de conflitos entre os novos e os antigos habitantes. Ao conjunto de conflitos resultantes deste contato entre mundos e culturas tão diferentes deu-se o nome de “Guerra dos Bárbaros”’. Sobre a Guerra dos Bárbaros ver Pires (1990) e Puntoni (2002).
} 
Não se tem muita evidência documental da existência de outros engenhos na capitania até início do século XIX, o que confirma seu desenvolvimento econômico menos dinâmico do que em outras capitanias cuja economia era voltada para a cana-de-açúcar. Entretanto, Sebastião da Rocha Pitta, ao escrever sua História da América portuguesa, publicada originalmente já em 1730, afirmou que o "recôncavo" do Rio Grande era "dilatadíssimo" e "teve mais engenhos dos que hoje permanecem, pelas ruínas que têm causado os gentios daquele vasto distrito, que são dos mais ferozes e bárbaros, e costumam repetidas vezes destruir as fábricas e lavouras dos moradores" (PITTA, 1976, p. 56). Além desse relato, outro documento utilizado por Andrade (1981), “Ideia geral da capitania de Pernambuco e suas anexas", publicado pelos Anais da Biblioteca Nacional, indica a existência de cinco engenhocas na cidade do Natal, "das quaes algumas delas fazem finos assucares de bom pezo" e haveria na vila e freguesia de São José de Mipibu 22 engenhocas que apenas produziriam mel e rapadura.

Durante o século XVIII, parece não ter havido nenhum tipo de incremento na indústria do açúcar na localidade. Na documentação publicada nos Anais na Biblioteca da Nacional, há uma descrição da capitania do Rio Grande. Nela, consta a existência de muitas fazendas distribuídas entre as quatro ribeiras, divisão administrativa pela qual a Fazenda Real se organizava. Entretanto, não é citada a presença de nenhuma fábrica de açúcar (ANAIS DA BIBLIOTECA NACIONAL, 1918). ${ }^{13}$

Alguns autores afirmam que houve um crescimento da economia do açúcar no final do século XVIII. A definição da capitania do Rio Grande como área canavieira, segundo Andrade (1981), começou a se moldar no último quartel do século XVIII, embora de forma modesta. Havia poucos engenhos e estes ainda utilizavam instalações de madeira. Existiam três engenhos na Freguesia de Natal e 22 engenhocas na Freguesia de São José do Mipibu, que produziam mel e rapadura (ANDRADE, 1981). Para este autor, na transição do século XVIII para o XIX, a produção do Rio Grande do Norte teria se diversificado. Além da criação de gado, fabricavam-se couro, algodão, rapadura e sal (ANDRADE, 1981). Infelizmente, o autor não menciona as fontes utilizadas.

Da mesma forma que Andrade coloca o final do século XVIII como um período de definição da vocação açucareira do estado, para Fátima Lopes (2005) e Monteiro (apud LOPES, 2005), teria havido, a partir de 1790, uma retomada da produção açucareira. Segundo Lopes, era utilizada mão de obra indígena "voluntária" (termo que aparece na documentação) no engenho Cunhaú. Já Denise Monteiro (apud LOPES, 2005) foi mais longe, ao afirmar que a retomada da produção açucareira na década de 1790 teria sido o motivo para o decréscimo da população indígena no Rio Grande. Em outra obra, Denise Monteiro (2007) afirma que o século XVIII foi caracterizado pela montagem das fazendas

\footnotetext{
13 Idéa da população da Capitania de Pernambuco, e das suas annexas, sua costas, rios, e povoações notaveis, Agricultura, numero de engenhos, contractos, e rendimentos reaes, augmento que estes tem tido \& ${ }^{a}$ a desde 0 anno de 1774 em que tomou posse do governo das mesmas capitanias o Governador e Capitam General Jozé Cezar de Menezes. (Anais da Biblioteca Nacional, 1918).
} 
de gado pertencentes a senhores de engenho da zona da mata açucareira residentes em outras capitanias ou em Cunhaú.

O principal problema ao desenvolvimento econômico do Rio Grande do Norte, segundo Andrade (1981), era a falta de boas estradas e de portos aparelhados. 0 autor afirma que a produção do Rio Grande do Norte era transportada para Recife para ser exportada.

Além da cidade do Natal, no século XVII, havia vários agrupamentos indígenas que posteriormente formariam os aldeamentos. 0 primeiro deles foi o de Guajiru, que seria mais tarde Extremoz. A existência desta aldeia foi notificada desde 1641, por um emissário holandês que viajava pelo Rio Grande (LOPES, 2003), mas foi fundada oficialmente como missão regular em 1679. Mipibu, criada em 1736, já aparecia na relação de 1646 do padre Manoel de Morais (LOPES, 2003). Já Guaraíras tornou-se missão regular em 1681. Apesar de Igramació, futura Vila Flor, ter sido criada somente em 1740, segundo Olavo de Medeiros Filho (apud LOPES, 2003), as informações mais antigas sobre a aldeia estão no mapa de Jacques de Vaulx de Claye, de 1579. Porém, no mapa feito por George Magrave, de 1643, há uma indicação de que a aldeia estaria despovoada.

Além de uma tentativa de inserir os indígenas na nova ordem colonial em formação, tais aldeias eram importantes por constituírem pequenos núcleos urbanos nos quais a produção de alimentos girava. Muito relevante para a capitania do Rio Grande foi a produção de farinha de mandioca, já utilizada pelos índios, que, no processo colonizador, tornou-se um dos principais elementos da alimentação da sociedade colonial, tendo em vista que não havia trigo no Brasil neste período.

Assim, ao longo do século XVII, a população da capitania do Rio Grande concentrava-se no litoral leste. A cidade do Natal era o único núcleo urbano oficial, embora existissem tanto aldeias indígenas quanto missões religiosas. Natal tinha uma população muito diminuta e, apesar de não se terem números, sabe-se que a maior parte vivia em áreas rurais.

A partir da segunda metade do século XVIII, com a transformação das aldeias indígenas em vilas, dentro da política pombalina, ${ }^{14}$ houve um pequeno incremento desses núcleos urbanos (LOPES, 2007). Este fato deveu-se à criação de algumas instituições políticas nessas vilas, como a câmara municipal, o que acabou atraindo outros moradores, além dos antigos grupos indígenas que viviam no local.

A criação das vilas de índios contribuiu também para a formação de freguesias (SILVA FILHO, 2012), a partir da fragmentação da freguesia de Nossa Senhora da Apresentação que, conforme já mencionado, foi a primeira existente na capitania e abarcava praticamente todo o seu território.

A necessidade de se criarem novas freguesias ocorreu pelo fato de haver um incremento da população e o próprio surgimento dos núcleos urbanos, decorrentes dos aldeamentos

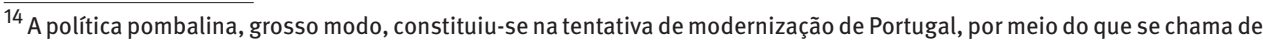
"despotismo esclarecido", pois buscava empregar mudanças inspiradas nos ideais iluministas, porém, com a manutenção do poder monárquico. Com relação à transformação dos aldeamentos em vilas, pensava-se na modernização e dinamização local a partir do estabelecimento de instituições políticas, administrativas e judiciais nessas áreas.
} 
indígenas. Somente no século XVIII seriam criadas dez freguesias, sendo cinco delas correspondentes às antigas missões.

As missões transformadas em vilas no litoral, a partir de 1758, foram: Guaraíras, que viria a ser Arêz; Guajiru, que viria a ser Extremoz; Mipibu, que viria a ser São José do Mipibu; e Igramació, que viria a ser Vila Flor (LOPES, 2005). Mas antes mesmo da criação dessas vilas de índios, foram instituídas as freguesias de São João do Assú, em 1726, justamente na região palco da Guerra do Açu, inserida na guerra mais ampla contra os "bárbaros", mostrando a necessidade de haver a presença de instituições religiosas, e a de Nossa Senhora dos Prazeres de Goianinha, em 1746, situada na região leste, o que de fato evidencia um adensamento da população que obrigou a existência de uma segunda freguesia no litoral, além da de Nossa Senhora de Apresentação.

As novas freguesias prosseguiram ao longo da segunda metade do século XVIII, mostrando como a Igreja católica estava atenta às necessidades de seus fiéis. Outras duas freguesias foram criadas no interior, uma em 1748, a de Sant’Ana de Caicó, e outra em 1753, a de Nossa Senhora da Conceição de Pau dos Ferros. Em seguida, algumas vezes coincidindo com a formação das vilas de índios, foram criadas, entre 1758 e 1764, as paróquias de Arêz, Estremoz, Portalegre, São José do Rio Grande (Mipibu) e Vila Flor (SILVA FILHO, 2012).

A criação de freguesias na capitania esteve diretamente relacionada a um crescimento populacional e econômico (MONTEIRO, 2007). Ao mesmo tempo, as várias freguesias criadas no litoral potiguar evidenciam uma maior dinamização da economia.

Em estudo recente para a região litorânea sobre alforrias de escravos no termo da vila de Arêz, que englobava Goianinha, no século XVIII, Aldinízia de Medeiros Souza (2013) verificou, por meio de inventários, que a maioria das escravaturas, ou seja, os senhores de escravos, era pequena e possuía de 1 a 5 escravos, correspondendo a 23 senhores, o que reforça o argumento de que nessa região havia o predomínio da pequena lavoura. Escravaturas médias, entre 6 e 14 escravos, pertenciam a oito senhores, enquanto as grandes, contando com 15 a 25 escravos, eram de apenas seis senhores. Nessa região, havia três engenhos reais (movidos à água) e 11 engenhocas no final do século XVIII. Ademais, em suas pesquisas, Souza (2013) analisou a procedência dos escravos alforriados e constatou que 35\% eram originários da África, evidenciando que no Rio Grande do Norte, a despeito de haver poucas áreas com características de grande lavoura, seus moradores compravam escravos trazidos diretamente da África. Infelizmente, não existem estudos para outras regiões do Rio Grande relativas ao período. Há uma indicação de Júlio de Senna $(1974$, v. 1) sobre dois fluxos migratórios de escravos para a região de Ceará Mirim. 0 primeiro teria ocorrido entre 1614 e 1698 com a vinda de 48 africanos. Já o segundo, 35 escravos teriam sido levados entre 1698 e 1760 . Porém, não há menção de onde esses dados foram retirados.

Os dados expostos denotam que a escravidão teve importância no Rio Grande do Norte. 0 pequeno número de escravos não é reflexo, como geralmente é afirmado, da pouca relevância do trabalho escravo na capitania do Rio Grande. Revela uma estrutura social 
na qual ocorreu uma convivência entre aquele tipo de relação de trabalho e a utilização da mão de obra livre, sem haver predominância de nenhuma das formas de trabalho. Isso pode ser explicado, inclusive, por não ter sido uma área agroexportadora que demandasse um grande contingente de escravos. Pode ser que existissem áreas ou certos tipos de atividade em que o trabalho escravo fosse mais utilizado. Em outras, pode ser que a mão de obra livre fosse a mais empregada. A questão é que a importância da escravidão é, comumente, relacionada ao seu papel nas lavouras de cana, grandemente consagrado pela historiografia e enraizado na memória brasileira. Mas ter escravos era importante do ponto de vista social, uma vez que ser senhor de escravos, bem como ser senhor de engenho, era um status almejado por todos, e que sobreviveria ao longo do século XIX.

Considerando esse histórico, percebe-se que o Rio Grande do Norte foi uma capitania que teve crescimento lento nos aspectos sociais e econômicos. Não foi um chamariz para imigrantes, nem teve atividades econômicas bastante dinâmicas que justificassem uma compra de escravos de forma maciça e constante.

Mas, a despeito desse crescimento lento, a tendência da população é sempre aumentar. Então, o que explicaria aquele decréscimo de $9 \%$ da população de 1801 em relação à de 1788 ? A década de 1790 vivenciou uma das primeiras grandes secas já registradas, apesar de sempre se darem ênfases nas secas da segunda metade do século XIX. Entretanto, na última década do século XVIII, houve uma temporada de seca que contribuiu para agravar o quadro, uma vez que a pecuária, que já vinha perdendo terreno para a produção do sul e era a atividade econômica mais importante para a renda da capitania, foi bastante afetada. A seca, acredita-se, também contribuiu para explicar alguns números de população encontrados. 0 clássico estudo de Caio Prado Júnior relaciona a estagnação da economia sertaneja nas capitanias do norte à produção local de Minas Gerais e à grande incidência das secas "no final do século XVIII em períodos mais ou menos espaçados, mas com regularidade dramática" (PRADO JR., 1994). A pecuária, entretanto, manteve uma regularidade durante todo período colonial, a partir de meados do século XVII, mesmo havendo períodos de crise e recuo nos valores dos volumes exportados. Segundo Charles Boxer (1969), as peles de boi eram um dos principais artigos da pauta de exportação. Assim, a atividade da pecuária sertaneja das capitanias do norte não estava atrelada "apenas" às minas. Segundo Alex Silva de Moura (2014), Caio Prado Júnior (1994) teria reduzido a importância do couro, uma vez que o considerava um subproduto, apesar de estar presente nos mapas de exportação.

Porém, correspondência encontrada no Arquivo Público da Bahia - duas cartas dirigidas ao governador da Bahia, escritas pela Câmara da Cidade do Natal - mostra a preocupação dos moradores da capitania com as dificuldades vivenciadas por eles. Reclamavam ainda de ordens vindas dos governadores de Pernambuco e da Bahia, solicitando que todo o gado que ainda estivesse vivo fosse levado a essas outras capitanias, cujos moradores estariam passando fome causada pela seca. Os habitantes do Rio Grande do Norte reclamavam justamente que eles também passavam por inúmeras dificuldades em virtude das grandes 
secas que assolavam o sertão e acarretavam a morte do gado e a falta de alimentos. ${ }^{15}$ Além disso, houve uma epidemia de bexiga (varíola), conforme mostra outro documento do Arquivo Histórico Ultramarino. ${ }^{16}$

Portanto, a seca provavelmente foi a causadora do decréscimo populacional ocorrido na capitania do Rio Grande do Norte. Agora falta compreender o motivo de um crescimento relativamente rápido em apenas cinco anos, uma vez que a população passou de 29.443 para 49.250 habitantes, entre 1801 e 1805, representando um aumento de 67,3\%.

Uma recuperação econômica em quatro anos, com o retorno de uma pecuária forte não é descartado. Interessante que a Paraíba, capitania vizinha, entre 1802 e 1805, teve uma diminuição de sua população, passando a apresentar índices de crescimento a partir de 1805, de acordo com os estudos de Yamê Paiva (2015). É possível que alguns moradores da capitania da Paraíba, bem como de outras, tivessem migrado para o Rio Grande do Norte, o que talvez explicasse esse aumento.

Fato é que, apesar de ser viável conjecturar sobre o decréscimo entre 1788 e 1801, com base na documentação, tal tarefa torna-se inglória para o período posterior. Entretanto, o exercício aqui proposto de articular novas metodologias da Demografia com a História permitiu melhor interpretar os dados, de forma preliminar, com o objetivo de articular os números apresentados com fontes primárias.

\section{Considerações finais}

0 artigo procurou analisar dados do último quartel sobre a capitania do Rio Grande do Norte. Apesar da incidência de sub-registros nos mapas de população, eles permitiram observar que, em 1801 e 1805, o número de pessoas pardas e pretas na população era superior ao de pessoas brancas, além de os escravos representarem cerca de $24 \%$ da população, em 1801, mostrando como o instituto da escravidão estava presente, apesar de a capitania do Rio Grande não ser produtora de gêneros que tinham interesse internacional.

Em relação à razão de sexo, a despeito de alguns momentos de pouco equilíbrio, pode-se afirmar que a população livre esteve medianamente equilibrada. Entre a população escrava, as oscilações foram maiores a partir do grupo etário de 50 a 59 anos, indicando a predominância de homens na população no final da vida adulta e idosa. Estes resultados revelam que os dados apresentam falhas em seus levantamentos, uma vez que, nestas idades, geralmente a quantidade de mulheres tende a ser superior à de homens, pois são menos propensas à mortalidade.

No sentido de entender uma diminuição da população entre 1788 e 1801, foram procuradas razões que explicassem esse fato. Na busca por documentos históricos e na historiografia, foram constatadas grandes secas no último decênio do século XVIII, o que teria levado a um aumento da mortandade, comprovada também nos dados observados

\footnotetext{
${ }^{15}$ APEB, Seção Colonial. Doc. 14763.

16 AHU-PA-Rio Grande do Norte, Cx. 8, D. 483.
} 
e estimados. Portanto, a junção de técnicas da demografia possibilitou apurar os dados demográficos e, com o auxílio da história, foi possível entender melhor os resultados.

\section{Referências}

ALDEN, D. The population of Brazil in the late eithteenth century: a preliminary study. The Hispanic American Historical Review, v. 43, p. 173-205, 1963.

ANAIS da Biblioteca Nacional. Rio de Janeiro: Biblioteca Nacional, 1923. Volume XL, 1918.

ANDRADE, M. C. de A. A produção do espaço norte rio-grandense. Natal: Editora Universitária/ UFRN-Proedi, 1981.

ARRAIS, R. P. A.; LUZ, D. C. S.; MARINHO, I. A. B.; ALVES, G. M. (Org.). Ceará-Mirim: tradição, engenho e arte. Natal: Sebrae/RN, UFRN, 2005. v. 1.

BATISTA, A. F. 0 sumário das armadas: guerras, missão e estratégias discursivas na conquista da Paraíba. Dissertação (Mestrado em História) - Universidade Federal do Rio Grande do Norte, Natal, 2012.

BOXER, C. R. A idade de ouro do Brasil: dores de crescimento de uma sociedade colonial. São Paulo: Companhia Editora Nacional, 1969.

CARVALHO, J. A. M. Evolução demográfica recente no Brasil. Pesquisa e Planejamento Econômico, v. 10, n. 2, p. 527-553, ago. 1980.

Crescimento populacional e estrutura demográfica no Brasil. Belo Horizonte: Centro de Desenvolvimento e Planejamento Regional - Cedeplar / UFMG, 2004 (Texto para discussão, n. 227).

CARVALHO, J.A. M.; SAWYER, D. O.; RODRIGUES, R. do N. Introdução a alguns conceitos básicos e medidas em demografia. São Paulo: Abep, 1998 (Série Textos Didáticos, n. 1).

CASCUDO. L. da C. A casa de Cunhaú. Brasília: Senado Federal, 2008 (Edições do Senado Federal, v. 45).

História da Cidade do Natal. 4. ed. Natal: Ed. da UFRN, 2010.

1984.

. História do Rio Grande do Norte. Natal: Fundação José Augusto; Rio de Janeiro: Achiamé,

CASTRO, P. V. de P. Dinâmica urbana de um município canavieiro: o caso de Ceará-Mirim-RN. Dissertação (Mestrado em Geografia) - Universidade Federal de Pernambuco, Recife, 1989.

CERQUEIRA, C. A.; GIVISIEZ, G. H. N. Conceitos básicos em demografia e dinâmica demográfica brasileira. In: RIOS-NETO, E. L. G.; RIANI, J. de L. (Org.). Introdução à demografia da educação. Campinas: Associação Brasileira de Estudos Populacionais, 2004.

CHALHOUB, S. Cidade febril. Cortiços e epidemias na corte imperial. São Paulo: Cia das Letras, 1996.

CLEMENTINO, M. do L. M. Economia e urbanização: o Rio Grande do Norte nos anos 70. Natal: UFRN-CCHLA, 1995.

COUNTING COLONIAL POPULATIONS: demography and the use of statistics in the Portuguese Empire 1776-1890. Disponivel em: 〈http://colonialpopulations.fcsh.unl.pt/index.html`. Acesso em: 31 jan. 2017.

DUSSEN, A. Van der. Relatório sobre o estado das Capitanias conquistadas no Brasil, redigido 
pelo senhor Adriaen van der Dussen, datado de 10 de dezembro de 1639 e apresentado ao Conselho dos XIX na Câmara de Amsterdam em 4 de abril de 1640. In: MELLO, J. A.G. de. Fontes para a história do Brasil holandês. Recife: Cepe, v.1, 2004.

EISENBERG, P. Modernização sem mudança: a indústria açucareira em Pernambuco 1840-1910. Rio de Janeiro: Paz e Terra; Campinas: Universidade Estadual de Campinas, 1977.

FARIA, S. de C. História da família e demografia histórica. In: FLAMARION, C.; VAINFAS, R. (Ed.). Domínios da História. Rio de Janeiro: Ed. Campus, 1997.

GOMES, R. de C. da C. Fragmentação e gestão do território no Rio Grande do Norte. Dissertação (Mestrado em Geografia) - Universidade Estadual Paulista, Rio Claro, 1997.

GONÇALVES, R. C. Guerras e açúcares: política e economia na capitania da Paraíba (1583-1630). Bauru: Edusc, 2007.

HENRY, L.; FLEURY, M. Nouveau manuel de depouillement et d' etat civil ancien. Paris: INED, 1965. IHGRN - Instituto Histórico e Geográfico do Rio Grande do Norte. Sesmarias do Rio Grande do Norte. Mossoró: Gráfica Tercio Rosado, v. 1, 2000 (Coleção Mossoroense, série c, vol. 1136).

JUDSON, D. H.; POPOFF, C. L. Selected general methods. In: SIEGEL, J. S.; SWANSON, D. A. (Ed.). The methods and materials of demography. 2. ed. New York: Elsevier Academic Press, 2004. p. 668-748.

LOPES, F. M. Em nome da liberdade: as vilas de índios do Rio Grande do Norte sob o diretório pombalino no século XVIII. Tese (Doutorado) - Universidade Federal de Pernambuco, Recife, 2005.

I Índios, colonos e missionários na colonização da capitania do Rio Grande do Norte. Mossoró: Fundação Vingt-un Rosado/IHGRN, 2003.

LYRA, A. T. de. História do Rio Grande do Norte. 3. ed. Natal: Ed. da UFRN, 2008.

MACHADO, C. A trama das vontades: negros, pardos e brancos na construção da hierarquia social do Brasil escravista. 1. ed. Rio de Janeiro: Apicuri, 2008. v. 1.

MARCÍLIO, M. L. Os registros paroquiais e a história do Brasil. Revista Varia Historia, n. 31, p. 13-20, 2004.

MARCíLIO, M. L. Crescimento demográfico e evolução agrária paulista, 1700-1836. São Paulo: Hucitec, 2000.

MATOS, P. T. de; SOUZA, P. S. A estatística da população na América portuguesa, 1750-1820. Revista Digital de Historia y Arqueología desde el Caribe Colombiano, Ano II, n. 25, p. 72-103, enero-abril 2015.

MEDEIROS, G. E. P. de. A auto-afirmação político-administrativa da capitania do Rio Grande do Norte no início do século XIX. Monografia (Graduação em História) - Universidade Federal do Rio Grande do Norte, Natal, 2011.

MEDEIROS, R. P. de. Povos indígenas nas guerras e conquistas do período colonial. CLIO - Série Revista de Pesquisa Histórica, n. 27-1, p. 331-361, 2009.

MEDEIROS, T. Estudos de história do Rio Grande do Norte. Natal: Tipografia Santa Cruz, 2001. MELLO, J. A. G. de. Fontes para a história do Brasil holandês. Recife: CEPE, 2004.

. A relação das praças fortes do Brasil (1609) de Diogo Campos Moreno. Revista do Instituto Arqueológico, Histórico e Geográfico Pernambucano, v. LVII, p. 177-246, 1984. 
MENDONÇA, S. R. de. O ruralismo brasileiro. São Paulo: Hucitec, 1997.

MONTEIRO, D. M. Introdução à história do Rio Grande do Norte. 3. ed. Natal: EDUFRN, 2007.

MOURA, A. S. de. 0 beneficiamento do couro e seus agentes na capitania de Pernambuco (1710 -1760). Recife: Universidade Federal de Pernambuco, 2014.

PAIVA, E. F. Histórias comparadas, histórias conectadas: escravidão e mestiçagem no mundo ibérico. In: PAIVA, E. F.; IVO, I. P. (Org.). Escravidão, mestiçagens e histórias comparadas. São Paulo: Annablume; Belo Horizonte: PPGH-UFMG; Vitória da Conquista: Edições UESB, 2008 (Coleção Olhares).

Dar nome ao novo: uma história lexical da Ibero-América entre os séculos XVI e XVIII (as dinâmicas de mestiçagens e o mundo do trabalho). Belo Horizonte: Autêntica, 2015.

PAIVA, Y. A demografia da Paraíba. Uma análise preliminar, 1774-1820. Anais de História de Além Mar, n. 16, p. 205-226, 2015.

PEREIRA, N. Imagens de Ceará-Mirim. 3. ed. Natal: Fundação José Augusto, 1989.

PIRES, M. I. C. Guerra dos bárbaros: resistência indígena e conflitos no Nordeste colonial. 1. ed. Recife: Fundarpe, 1990.

PITTA, S. da R. História da América portuguesa. Belo Horizonte: Ed. Itatiaia; São Paulo: Ed. da Universidade de São Paulo, 1976 [1730].

PRADO JR., C. Formação do Brasil contemporâneo. 23. ed. São Paulo: Editora Brasiliense, 1994.

PUNTONI, P. A guerra dos bárbaros: povos indígenas e a colonização do sertão Norte do Brasil, 1650-1720. São Paulo: Hucitec / Edusp, 2002.

RECENSEAMENTO IMPERIAL DE 1872. Disponivel em: 〈http://www.nphed.cedeplar.ufmg.br/ pop72>. Acesso em: 10 mar. 2017.

RIBEIRO, P. H. M. Escravos e sua senhora: estudo dos cativos da família Albuquerque Maranhão (1823). Monografia (Graduação em História) - Universidade Federal do Rio Grande do Norte, Natal, 2012.

RODARTE, M. M. S. 0 trabalho do fogo: perfis de domicílios enquanto unidades de produção e reprodução de Minas Gerais Oitocentista. Tese (Doutorado em Demografia) - Centro de Desenvolvimento e Planejamento Regional, Universidade Federal de Minas Gerais, Belo Horizonte, 2008.

SANTOS, J. da S. M. A expansão canavieira no vale do Ceará Mirim 1845-1930. Monografia (Graduação em História) - Universidade Federal do Rio Grande do Norte, Natal, 2001.

SANTOS, P. P. dos. Evolução econômica do Rio Grande do Norte: séculos XVI ao XX. Natal: Clima, 1994.

SCHWARCZ, L. K. M. Homem de sciencia e a raça dos homens: cientistas, instituições e teorias raciais em finais do século XIX. Tese (Doutoramento) - Universidade de São Paulo, São Paulo, 1993.

SCHWARTZ, S. B. Segredos internos: engenhos e escravos na sociedade colonial. São Paulo: Companhia das Letras, 1988.

SHRYOCK, H. S.; SIEGEL, J. S. The methods and materials of demography. San Diego: Academic Press, 1976.

SENNA, J. G. de. Ceará-Mirim: exemplo nacional (1938-1972). Rio de Janeiro: Pongetti, 1974. 2 v. 
SILVA FILHO, J. R. da. Os homens de Deus na terra dos homens: os vigários seculares na capitania do Rio Grande no século XVIII. Monografia (Graduação em História) - Universidade Federal do Rio Grande do Norte, Natal, 2012.

SOARES, F. M. Levantamento do uso da terra e perspectivas agrícolas no município de Ceará-Mirim - RN através de técnicas de sensoriamento remoto. Dissertação (Mestrado em Geografia - Organização do Espaço) - Instituto de Geociências e Ciências Exatas, Universidade Estadual Paulista, Rio Claro, 1985.

SOUZA, A. de M. Liberdades possíveis: escravidão e alforria no termo da vila de Arez (séculos XVIII e XIX). Dissertação (Mestrado em História) - Universidade Federal do Rio Grande do Norte, Natal, 2013.

. 0 culto religioso produzindo novos territórios: a (re)invenção de Cunhaú. Monografia (Graduação em História) - Universidade Federal do Rio Grande do Norte, Natal, 2005.

SOUZA, I. de. A República Velha no Rio Grande do Norte (1889-1930). Natal: Centro Gráfico do Senado Federal, 1989 (edição comemorativa do primeiro centenário da Proclamação da República do Brasil).

VIANA, L. 0 idioma da mestiçagem: as irmandades de pardos na América portuguesa. Campinas: Editora da Unicamp, 2007.

\title{
Sobre as autoras
}

Dayane Julia Carvalho Dias é doutoranda em Demografia na Universidade Estadual de Campinas (Unicamp) e mestre em Demografia pela Universidade Federal do Rio Grande do Norte (UFRN).

Carmen Margarida Oliveira Alveal é doutora pela Johns Hopkins University. Professora do Departamento de História da Universidade Federal do Rio Grande do Norte (UFRN) e atua nos Programas de Pós-graduação em História da UFRN e Universidade Federal do Ceará (UFC).

\section{Endereço para correspondência}

\author{
Dayane Julia Carvalho Dias \\ Rua Félix Barbalho, 126, Boa Vista \\ 59173-0000 - Goianinha-RN, Brasil \\ Carmen Margarida Oliveira Alveal \\ Rua Getúlio Lopes de Araújo, 341, casa 22, Condomínio Graçandu I, Ponta Negra \\ 59091-100 - Natal-RN, Brasil
}




\begin{abstract}
A preliminary study of the demography of colonial Rio Grande do Norte: sources, methods and results

This article intends to conduct a dialogue between Demography and History, combining the specific knowledge of these disciplines in order to better understand both the numbers collected for the population of Rio Grande do Norte and the historical context which would explain those numbers. The purpose of this article is to present socio-demographic characteristics of the Rio Grande do Norte's population at the turn of the eighteenth century to the nineteenth, through the first population maps created in the second half of the eighteenth century, as part of the Pombal policy attempt to better understand the Portuguese empire. Furthermore, this paper seeks to present some demographic data, such as population composition by sex, color / ethnicity and legal status, of the Rio Grande do Norte captaincy, based on data produced in 1782, 1788, 1801 and 1805 , using Demography methodologies which will be explained through direct dialogue with the area's historiography.
\end{abstract}

Keywords: Rio Grande do Norte. Population. $18^{\text {th }}$ century.

\title{
Resumen
}

Un estudio preliminar de la demografía de Rio Grande do Norte: fuentes, métodos y resultados

Este artículo tiene la intención de plantear un diálogo entre la Demografía y la Historia, combinando la experiencia de estas disciplinas con el fin de aportar una mejor comprensión tanto de los números que se han logrado reunir sobre la población de Rio Grande como del contexto histórico que los explicarían. Por lo tanto, el objetivo de este artículo es presentar las características sociodemográficas de la población riograndese del norte desde fines del siglo XVIII hasta el siglo XIX a través de los primeros mapas de población de la segunda mitad del siglo XVIII, parte del intento de la política pombalina para conocer mejor el imperio portugués, y proporcionar algunos datos demográficos como la composición de la población por sexo, raza-etnia y condición jurídica de la capitanía de Rio Grande do Norte, con base en los datos producidos en 1782, 1788, 1801 y 1805, utilizando metodologías de la Demografía que serán explicitadas a lo largo del trabajo y en diálogo directo con la historia de la región.

Palabras clave: Rio Grande do Norte. Población. Siglo XVIII. 
